\title{
AMPLITUDE VARIATIONS OF THE REFLECTED SIGNAL DURING VERTICAL SOUNDING OF THE IONOSPHERE AT MIDDLE LATITUDES
}

\section{K.M. Yusupov}

Kazan Federal University,

Kazan, Russia,ukm84@mail.ru, kamil.usupov@kpfu.ru

\section{J.D. Mathews}

The Pennsylvania State University, UniversityPark,USA,jdm9@psu.edu

\section{T. Maruyama}

Kazan Federal University,

Kazan,Russia,tmaru@nict.go.jp

National Institute of Information

and Communications Technology,

Tokyo,Japan,tmaru@nict.go.jp

\section{A.A. Akchurin}

Kazan Federal University,

Kazan, Russia, adel.akchutin@kpfu.ru

\section{M.V. Tolstikov}

Institute of Solar Terrestrial Physics SB RAS,

Irkutsk,Russia,maxim@iszf.irk.ru

O.N. Sherstyukov

Kazan Federal University,

Kazan, Russia, oleg.sherstyukov@kpfu.ru

\section{E.A. Filippova}

Kazan Federal University,

Kazan, Russia, elena.filippova@kpfu.ru

A.S. Safiullin

Kazan Federal University,

Kazan, Russia, metskeysutemy@mail.ru

\begin{abstract}
Absract. In this paper, we discuss the main types of quasiperiodic variations in amplitudes of a reflected signal during vertical sounding of the ionosphere at middle latitudes. The initial experimental data is vertical sounding ionograms obtained by the Cyclone ionosonde. The ionosonde is located in Kazan $\left(59^{\circ}, 49^{\circ}\right)$ and in standard mode allows us to receive one ionogram per minute. In the analysis, methods are used to visualize a large flow of ionograms in the form of final summary maps of the state of the ionosphere (A-, $\mathrm{H}-, \mathrm{A}_{\mathrm{s}}$-maps). We give typical examples of quasiperiodic variations in amplitudes of a reflected signal in ionograms and on Amaps for various types of multipath beatings (polarization and due to signal scattering by ionospheric irregu-
\end{abstract}

\section{INTRODUCTION}

Research on the sporadic E layer has been going on for many decades [Mathews, Bekeny, 1979, 1998; Budden, 1961; Whitehead, 1989; Haldoupis, 2003, Haldoupis, Haldoupis 2011; Bakhmet'eva, 1999, 2005; Chkhetiani, Shalimov, 2013; Shalimov, 2014, etc.]. The sporadic E layer is distinguished by high intensity on the one hand (the electron density in the $\mathrm{E}_{\mathrm{s}}$ layer can be several times higher than that in the surrounding regular E layer), and, on the other hand, it is very thin (several $\mathrm{km})$. In connection with these features, unlike other layers of the ionosphere this layer has a frequency dependence of the height and amplitude of reflections. Therefore, in the 70-80s of the 20th century, studies into the amplitude-frequency characteristics (AFC) of reflections from the $\mathrm{E}_{\mathrm{s}}$ layer during vertical sounding of the ionosphere were popular. Of particular interest was the pattern of quasiperiodic beatings on $\mathrm{AFC}$ due to the interference or coupling of several magnetoionic modes. Such beatings are called polarization fading. The main studies of polarization fading on the frequency response of the $\mathrm{E}_{\mathrm{s}}$ layer were carried out in [Chessel, 1971a, b; larities). Frequency properties of such beatings are used to estimate the difference in virtual reflection heights between modes of different polarizations with high accuracy, which makes it possible to refine the form of the electron density profile of the lower ionosphere. We have detected a phenomenon rare for the mid-latitude $\mathrm{E}_{\mathrm{s}}$ layer - beatings of two $\mathrm{O}$ modes with different virtual reflection heights. We also present features of quasiperiodic variations in amplitudes of a reflected signal on traces of the transient $E_{\mathrm{s}}$ layer. We study possible causes of the appearance of such beatings.

Keywords: ionosonde Cyclone, ionogram, ionosphere, interference of reflected signals.

Turunen, 1980; Jalonen, 1981]; and for reflections from the F layer, in [Drobzhev, 1975].

Chessel [1971a, b] considered the semitransparent ranges of the sporadic $\mathrm{E}_{\mathrm{s}}$ layer in terms of the coupling mechanisms of magnetoionic modes, and presented model calculations of the reflection, transmission, refraction coefficients, and semithickness of the $E_{\mathrm{s}}$ layer under various geophysical conditions. Jalonen [1981] analyzed vertical sounding ionograms from highlatitude stations, found experimental evidence of beatings on the frequency response of the $E$ and $E_{s}$ layers, and observed a decrease in the step between successive interference minima. Such beatings were interpreted in terms of interference and coupling of two magnetoionic modes with ordinary polarization. At middle latitudes, the $E_{\mathrm{s}}$ traces are characterized by an increase in the steps between successive interference minima, and fading is usually explained by the interference of the $\mathrm{O}$ and $\mathrm{X}$ modes [Yusupov, 2011; Akchurin and Yusupov, 2011b]. Due to the very small thickness (few km) of the $\mathrm{E}_{\mathrm{s}}$ layer, it is extremely difficult to distinguish between the interference of the $\mathrm{O}$ and $\mathrm{X}$ modes and the interference of two $\mathrm{O}$ modes. The task is simplified if we draw 
an analogy with beatings on the traces of the F layer, which were studied in detail in [Drobzhev, 1975]. We examine beatings during reflections from the ionosphere at middle latitudes, both already described and previously undescribed, in order to generalize all types of polarization beatings. This work was made possible thanks to features of the Cyclone ionosonde control system.

\section{Equipment and methods for visualizing vertical sounding data of the ionosphere}

The initial experimental data is vertical sounding ionograms obtained by the Cyclone ionosonde (Kazan, $\sim 59^{\circ} \mathrm{E}, 49^{\circ} \mathrm{N}$ ). To study the rapidly changing processes occurring in the ionosphere, the ionosonde Cyclone control system was updated in February 2010 [Akchurin, 2010]. After the modernization, the ionosonde has the following characteristics: 1) the peak power of the sounding signal is $\sim 10 \mathrm{~kW}$. 2) the sounding pulse duration is $70 \mu \mathrm{s}$. 3) the sounding frequency range is 1-9 MHz. 3) the sounding time is $20 \mathrm{~s}$. In the standard mode, the Cyclone ionosonde receives one ionogram per minute. The ionosonde has a crossed delta antenna with a height of $\sim 10 \mathrm{~m}$ (one arm of the antenna works for transmitting; and the other, for receiving). The ionosonde does not have a system for separating polarization modes during receiving. On the one hand, it allows analyzing amplitude variations of reflected signals during polarization fading we describe. On the other hand, it makes it difficult to automatically extract traces of reflections on the ionogram, which is necessary for reconstructing electron density profiles.
Currently, there are no reliable fully automatic methods (without operator) for obtaining vertical electron density profiles from vertical sounding ionograms. Therefore, on the one hand, the high temporal resolution of the Cyclone ionosonde (1 ionogram per minute) makes it possible to obtain new data on the dynamics of the ionosphere; on the other hand, it is extremely difficult to provide manual processing of such a large amount of data. To solve this problem, Kazan Federal University has developed algorithms for visualizing a large flow of ionograms in the form of summary maps of the state of the ionosphere (A-, H-, As-maps) [Yusupov, 2011; Akchurin and Yusupov, 2011a].

The A-map (amplitude map) is time variations in AFC of a reflected signal, the H-map (height map) is time variations in the height-frequency characteristics (HFC) of a reflected signal, the $\mathrm{A}_{\mathrm{s}}$-map is time variations in the summary amplitude (over all frequencies) of a reflected signal. The $\mathrm{A}_{\mathrm{s}}$-map is similar to radar methods of observing the ionosphere and to the well-known forms of representations of the results of vertical sounding in the form of RTI-images [Haldoupis, 2006; Lynn, 2011; Harris, 2016; Kozlovsky et al., 2018], A-map is also similar to an FTI-image [Kozlovsky et al., 2018]. Figure 1 illustrates the process of obtaining summary maps of the state of the ionosphere. Figure 1, $a$ gives an example of an ionogram. To obtain A-maps, maximum amplitudes for each frequency are identified (Figure 1, $b$ ); to obtain H-maps, heights corresponding to maximum amplitudes are searched for (Figure 1,d); and to obtain As-maps for each height, the total amplitude for all frequencies is found (Figure $1, e$ ).

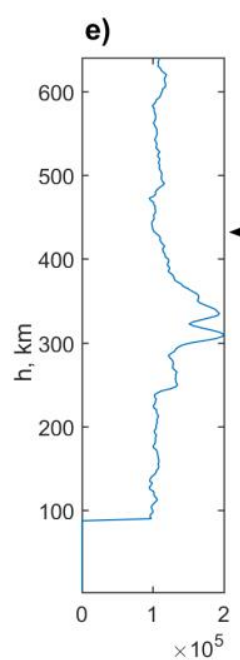

a)

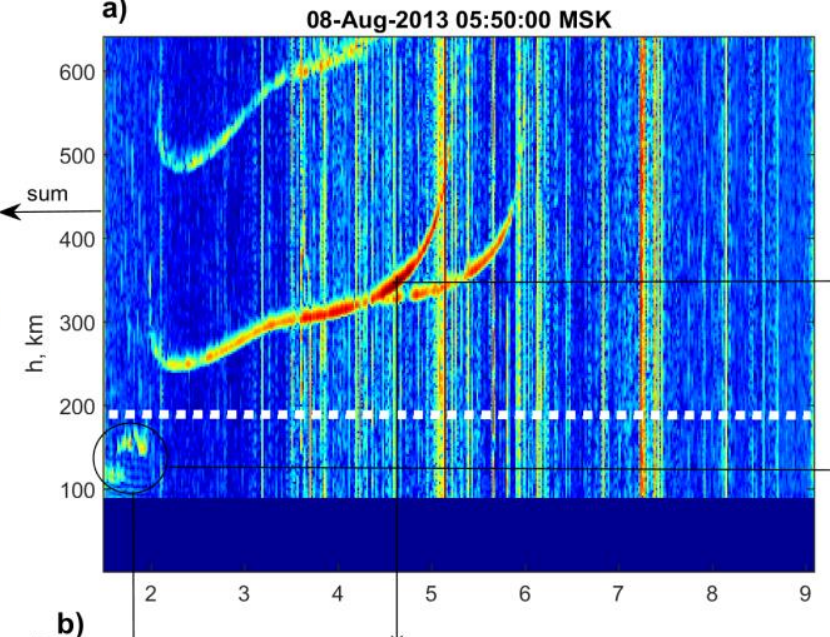

d)
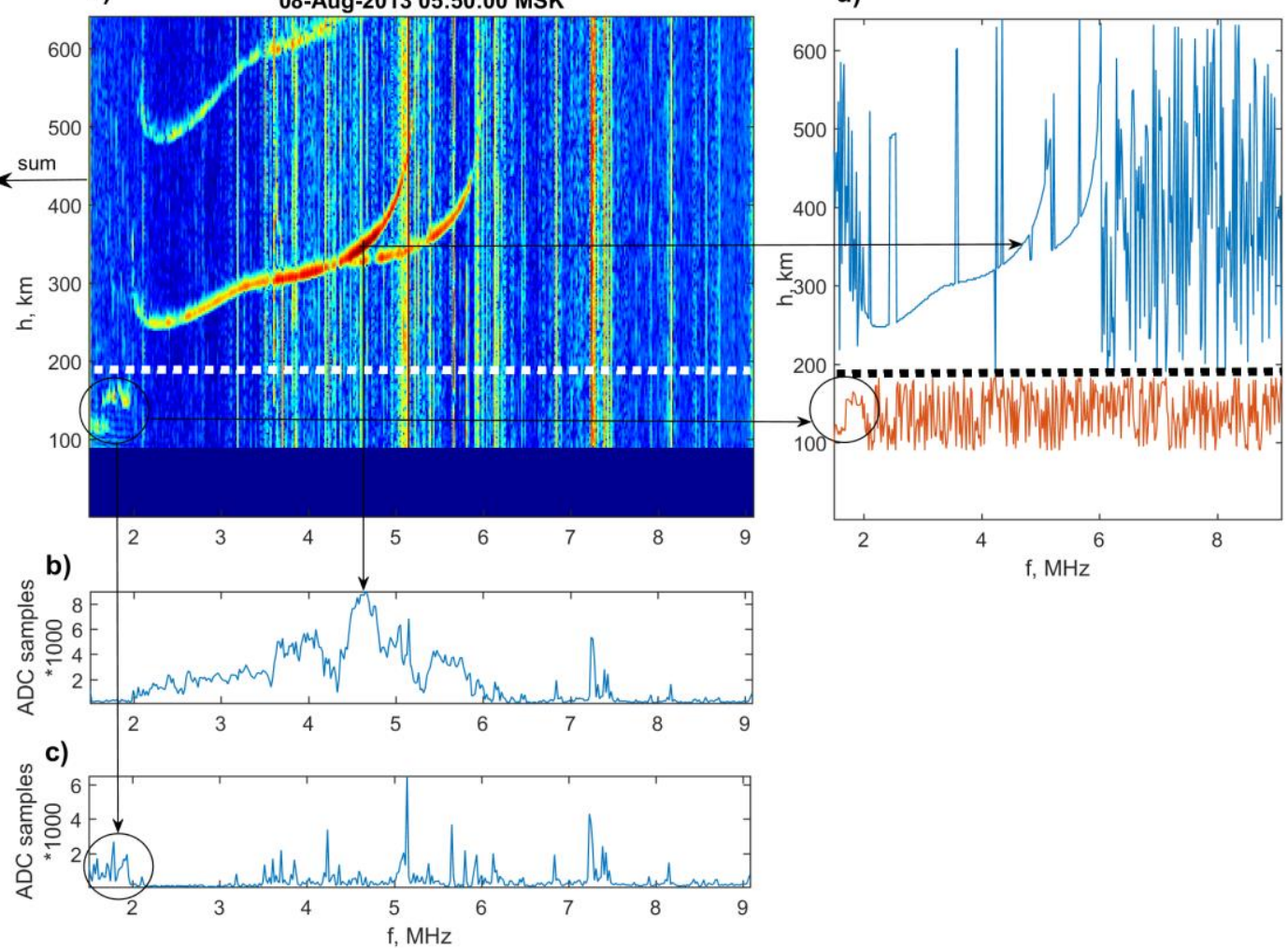

Figure 1. Diagram of the algorithm for obtaining summary maps of the state of the ionosphere: $a-$ ionogram; $b-\mathrm{AFC}$ of the F layer; $c-\mathrm{AFC}$ of the E layer; $d-\mathrm{HFC}$ of the F and E layers; $e-$ height histogram obtained by summing all the amplitudes of the ionogram along the frequency axis 
Further, for each moment of time (for the corresponding ionogram), such procedure is repeated. When constructing A- and H-maps separately for the E- and Fregions, the ionogram is divided into two altitude intervals $1-200 \mathrm{~km}$ and $200-600 \mathrm{~km}$ respectively. Figure 2 shows summary maps of the state of the ionosphere for August 22, 2013.

Figure 2 presents the summary maps of the state of the ionosphere that clearly illustrate variations in the amplitude of a reflected signal, variations in the height of a reflected signal, and variations in the virtual heights of the ionospheric layers. By using the summary maps, we can easily analyze variations in the critical frequencies of the ionospheric layers. In this paper, we use the summary maps of the state of the ionosphere to study beatings in ionospheric traces during vertical sounding.

\subsection{Amplitude variations in signals reflected from the $F$ layer}

Drobzhev et al. [1975] have studied in detail beatings (polarizing fading) during signal reflection from the $\mathrm{F}$ layer and have shown that they can serve as an additional source of information on the background concentration of the lower ionosphere. The authors have also analyzed variations of the zero beating point (the sounding frequency where the difference in the virtual heights of the $\mathrm{O}$ and $\mathrm{X}$ modes tends to zero). Unfortunately, these works were carried out using an analogue technique. The data was not stored on a digital medium device, but was analyzed using photos of oscillograms.

Figure 3 provides an example of an ionogram from the Cyclone ionosonde $(a)$ with beatings occurring when
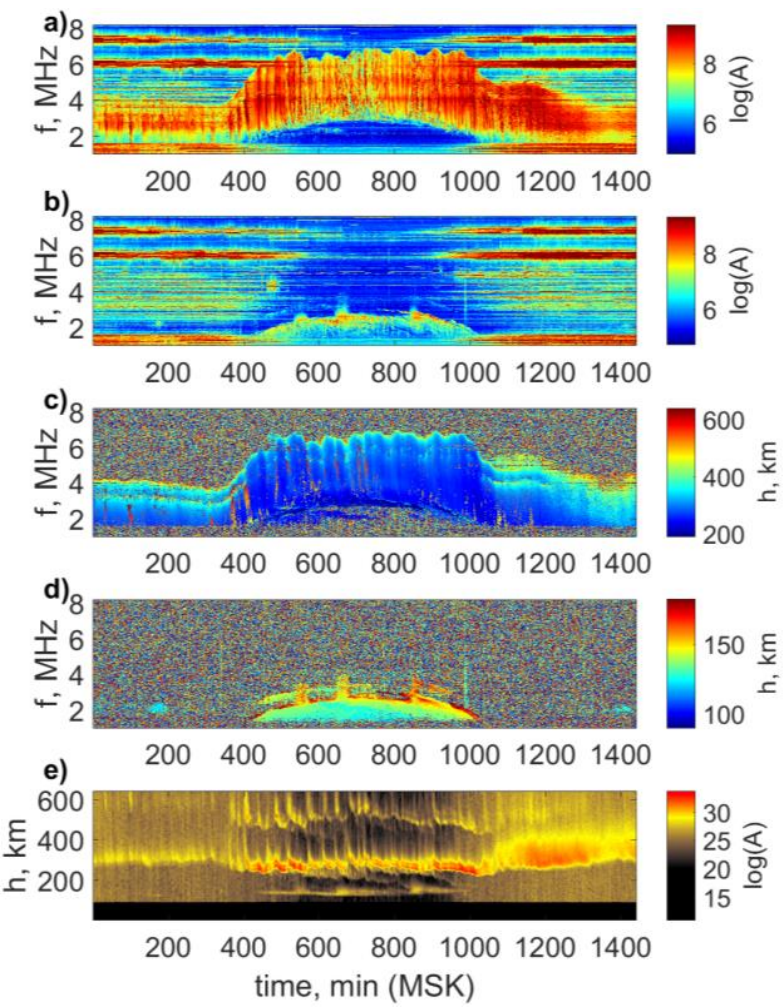

Figure 2. A-map of the F-region (a); A-map of the Eregion $(b)$; H-map of the F-region (c); H-map of the E-region $(d) ; \mathrm{A}_{\mathrm{s}}$-map (e)
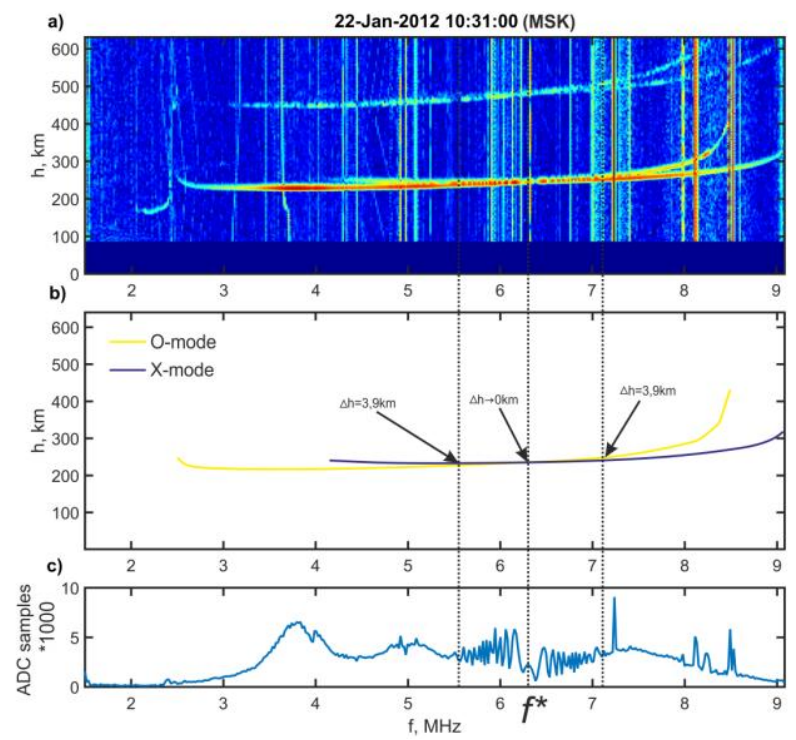

Figure 3. An ionogram with beatings of $\mathrm{O}$ - and X-mode types on traces of the F layer $(a)$; HFC of the O- and X-modes of traces of the F layer $(b)$; AFC of the F layer for this ionogram that pictures the polarization fading $(c) . f^{*}$ is the frequency of zero beatings

a signal is reflected from the $\mathrm{F}$ layer (similar to the $\mathrm{O}$ and $\mathrm{X}$ modes). A point of zero beatings $f^{*}$ is given. A characteristic feature of the AFC variations in reflection from the $\mathrm{F}$ layer is the presence of two intervals with different properties. In the first interval (before the point of zero beatings), a sequential increase in the frequency difference between the minima is observed; and in the second (after the point of zero beatings), a sequential decrease in the frequency difference between the minima. The point of zero beatings itself is either a minimum or a maximum, with a pattern in the form of a ring formed on the A-map (Figure 4,a). When the F layer split into F1 and F2, we can observe beatings both when the signal is reflected from the F1 layer and when it is reflected from the F2 layer (Figure 4, b). When the signal is reflected from the $\mathrm{F}$ layer, we can also see the beatings of the $\mathrm{O}$ - and $\mathrm{Z}$-modes (when the trace of the extraordinary Z-mode is located in the lower frequency region relative to the $\mathrm{O}$-mode), but for middle latitudes this is an extremely rare phenomenon; it is more typical of polar latitudes. The frequency distance between the minima at which the quasiperiodic variations begin is $38 \mathrm{kHz}$. Application of the formula $\Delta h=\mathrm{c} /(2 \Delta f)$ gives a difference in the virtual reflection heights of $\sim 3.9 \mathrm{~km}$ between the ordinary and extraordinary modes. Thus, the beatings begin (end) as the traces of different polarization move closer to each other (move away from each other) by $\sim 3.9 \mathrm{~km}$, with sounding pulse duration being $70 \mu \mathrm{s}$. In addition to the high-frequency amplitude variations in the reflected signal associated with the coupling of $\mathrm{O}$ - and X-modes, low-frequency AFC variations during the passage of traveling ionospheric disturbances (TIDs) are clearly seen on the A-maps of the F layer. These AFC variations are linked to an increase in the amplitude of the signal reflected from the electron density maxima formed during the passage of TIDs. In Figure 4, the TID-associated low-frequency AFC variations are 

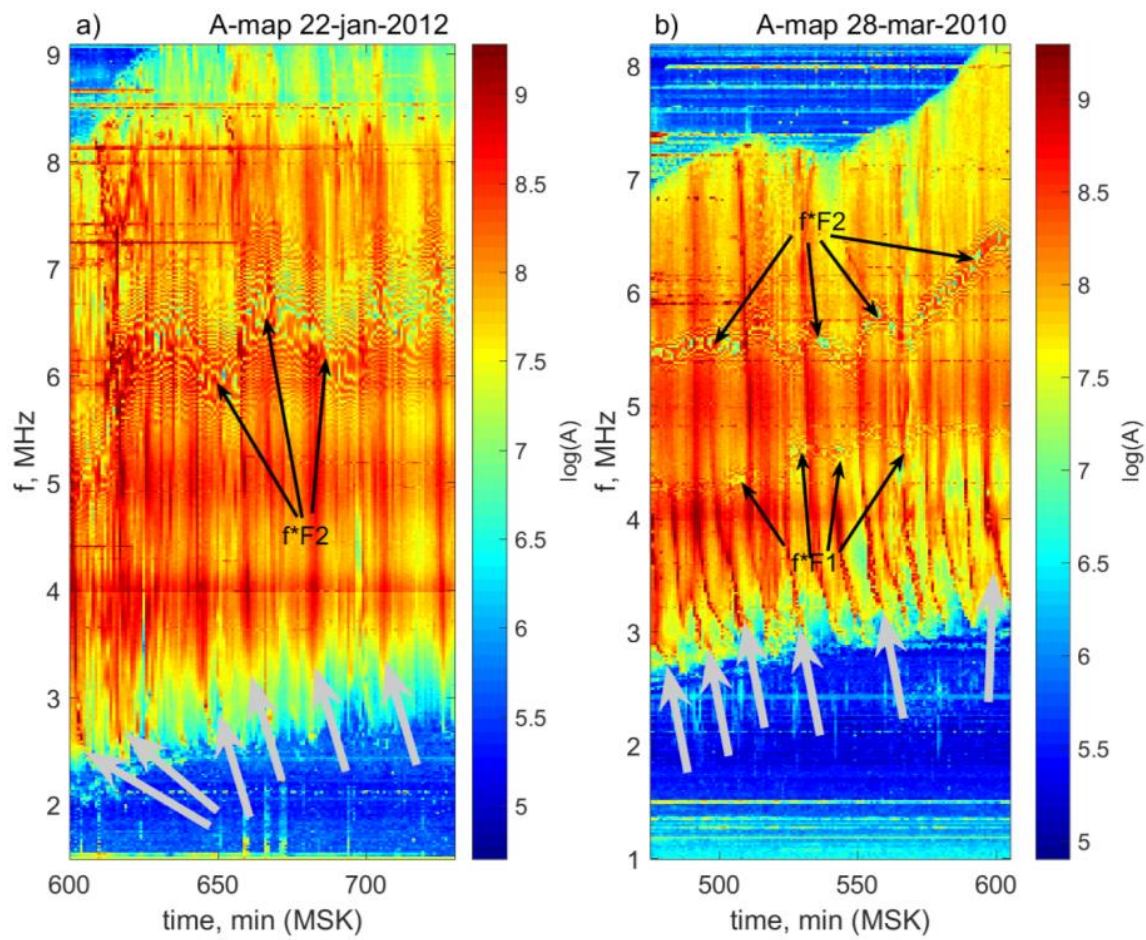

Figure 4. Polarization fading of the O- and X-modes on A-maps for the F2 layer (a) and simultaneously for F1 and F2 (b). For clarity, black arrows indicate frequency variations of the zero beating point, and gray arrows denote an increase in amplitude due to the passage of TIDs

indicated by gray arrows. The As-maps show traces of the passage of TIDs in the form of inclined strips (for example, Figure 2,e).

\subsection{Variations of signal amplitudes during reflection from the $\mathrm{E}_{\mathrm{s}}$ layer ( $\mathrm{O}$ - and $\mathrm{X}$-modes)}

Amplitude variations during beatings of the $\mathrm{O}$ - and $\mathrm{X}$-modes can also be observed when the signal is reflected from the sporadic layer Es, provided that the plasma frequency of the layer exceeds the reflection frequency of an ordinary wave by half the electron gyrofrequency [Yusupov, 2011]. The ionogram traces of $\mathrm{E}_{\mathrm{s}}$ at middle latitudes are almost strictly horizontal. The dispersion inclination or cusp is seen only in the daytime at the low-frequency end of the $\mathrm{E}_{\mathrm{s}}$ layer trace, both for the $\mathrm{O}$ - and $\mathrm{X}$-modes. The cusp of the unusual $\mathrm{E}_{\mathrm{s}}$ trace at the high-frequency end of the trace is in most cases not visible on vertical sounding ionograms due to blanketing by the trace of the ordinary component. Hence, during signal reflections from the $\mathrm{E}_{\mathrm{s}}$ layer, beatings will usually be observed only up to the sounding frequency, where the difference in the virtual heights of the $\mathrm{O}$ - and $\mathrm{X}$-modes tends to zero (zero beating points). Thus, in most cases, there will be a sequential increase in the frequency difference between the minima (in contrast to reflections from the $\mathrm{F}$ layer). An example of such beatings when reflected from $\mathrm{E}_{\mathrm{s}}$ is shown in Figure 5. We can see from the Figure that the beatings start at $\sim 4.5 \mathrm{MHz}$, which corresponds to the difference in effective heights of $\sim 5 \mathrm{~km}$ between traces, and end at $\sim 6.2$ $\mathrm{MHz}$, which corresponds to the difference in effective heights of $\sim 0.6 \mathrm{~km}$ between traces. Figure $6, a$ presents an A-map corresponding to the beatings shown in Figure 5.

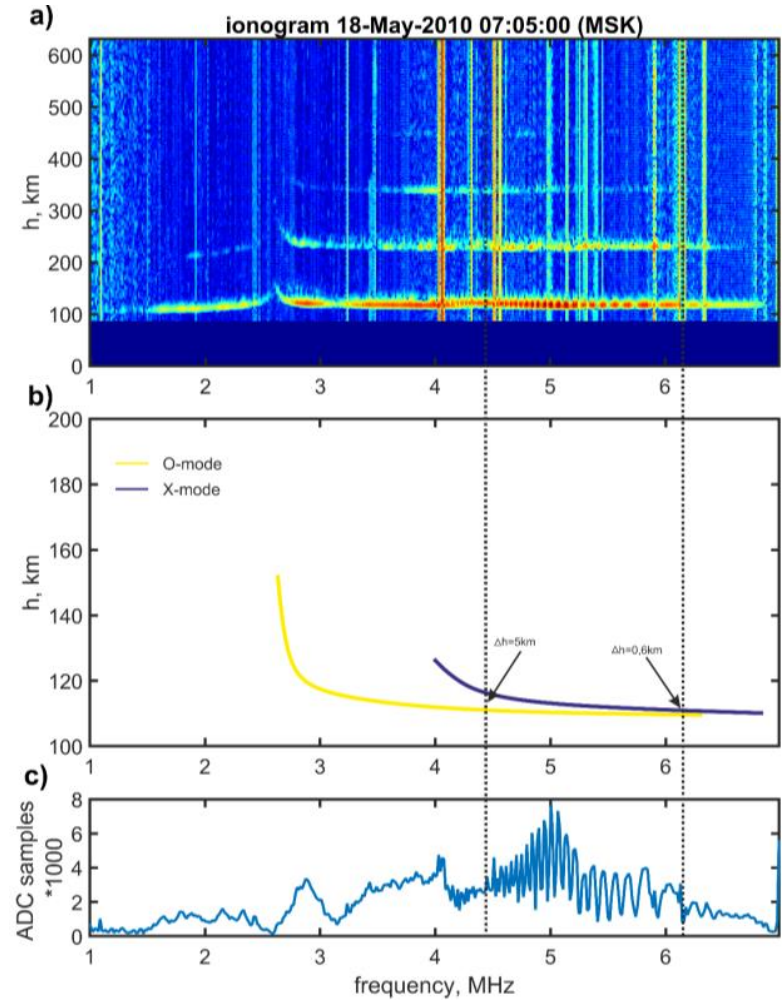

Figure 5. An ionogram with amplitude variations during beatings of $\mathrm{O}$ - and X-mode types on traces of the $\mathrm{E}_{\mathrm{s}}$ layer $(a)$; $\mathrm{HFC}$ of the O- and X-modes of traces of the $\mathrm{E}_{\mathrm{s}}$ layer (for clarity, the height axis is enlarged relative to the ionogram) $(b)$; $\mathrm{AFC}$ of the $\mathrm{E}_{\mathrm{s}}$ layer for the ionogram that pictures the polarization fading. Dotted lines mark the beginning and end of frequency boundaries of the beating range. Arrows indicate the difference in the effective heights between the O- and Xmodes at boundaries of the beating range $(c)$ 

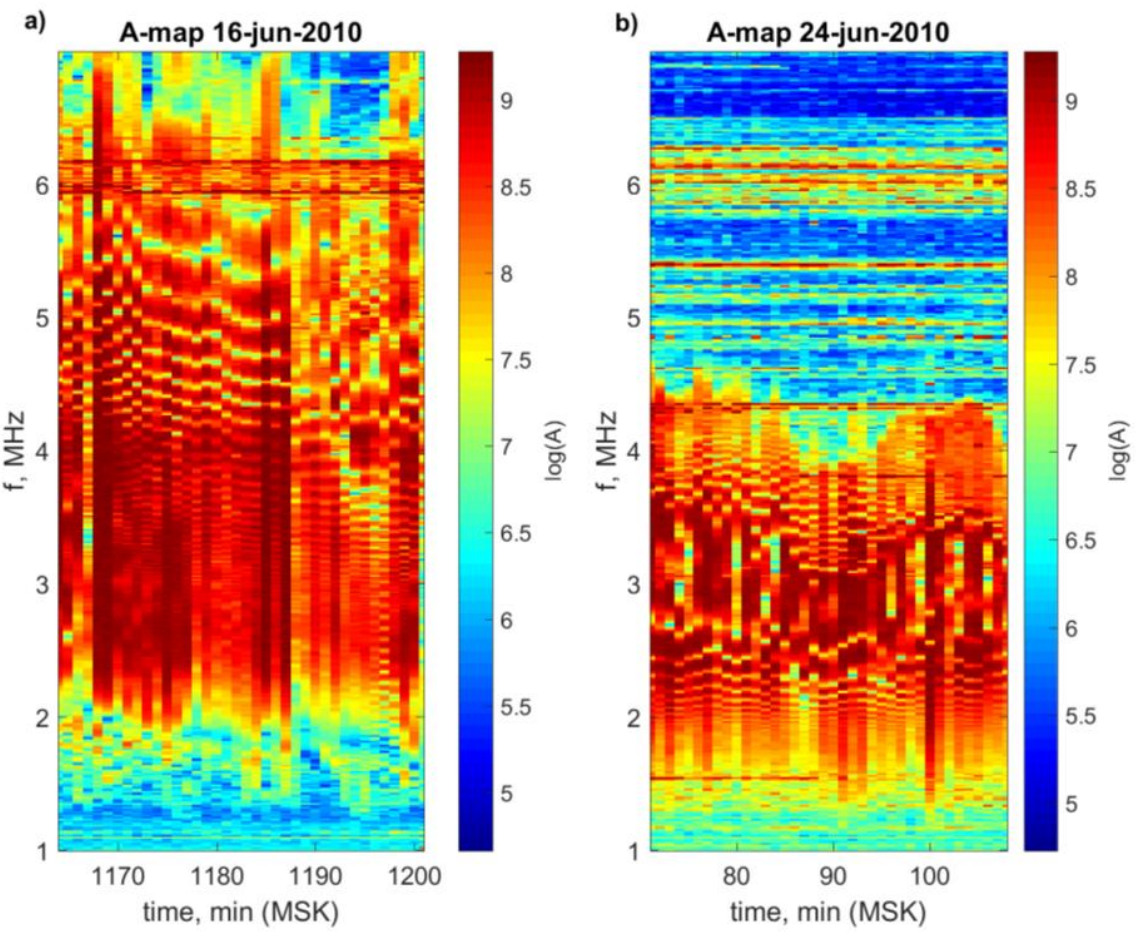

Figure 6. Polarization fading of the $\mathrm{O}$ - and $\mathrm{X}$ modes on A-maps for the $\mathrm{E}_{\mathrm{s}}$ layer: an increase in step between successive minima $(a)$; presence of an increase and a decrease in the step, and the frequency interval between the two types of beatings corresponds to the zero beating point and forms a pattern in the form of a "ring", similar to the pattern in F-layer traces $(b)$.

Figure $6, b$ shows a very rare case of beatings in the Es-layer traces, which are observed both before and after the point of zero beatings. When the X-trace moves closer to the O-trace, there is an increase in the frequency difference between the minima. When the $\mathrm{X}$ trace moves away from the O-trace, the frequency difference between the minima decreases. In the region of zero beatings, a characteristic pattern in the form of successive "rings" is observed. For this case we can determine the point of zero beatings with high accuracy, and hence the minimum distance between $\mathrm{O}$ - and $\mathrm{X}$ traces. The middle of the frequency interval between the last minimum of the "step increasing range" and the first minimum of the "step decreasing range" is the point of zero beatings. As mentioned above, such a pattern of fading of Es-layer traces is extremely rare at middle latitudes and is more characteristic of equatorial latitudes due to the higher electron density in the $\mathrm{E}_{\mathrm{s}}$ layer. Furthermore, at middle latitudes, the observation and analysis of such pattern of beatings is difficult due to technical limitations. Figure $6, b$ shows that the polarization fading pattern changes very quickly, therefore we cannot reduce the ionogram repetition rate. On the other hand, there is a need for a small step between sounding frequencies and a wide sounding frequency range (for example, 1-30 MHz), which requires a rather complicated ionosonde control system and leads to a decrease in the ionogram repetition rate.

\subsection{Amplitude variations in signals reflected from the $\mathrm{E}_{\mathrm{s}}$ layer (two O-modes)}

Quasiperiodic variations in $\mathrm{AFC}$ of the $\mathrm{E}$ and $\mathrm{E}_{\mathrm{s}}$ layers similar to the coupling of two O-modes at polar latitudes were studied in [Jalonen, 1981], and attempts to find such beatings were made in [Sherstyukov, 1989]. These works were based on the theory described in [Chessel, 1971a, b], where the appearance of the second $\mathrm{O}$-mode is explained as part of the mode coupling process. For oblique magnetic field lines and a steep gradient of the electron density of the $\mathrm{E}$ and/or $\mathrm{E}_{\mathrm{s}}$ layers a part of reflection energy of the O-mode is transformed into the X-mode, which is reflected at a slightly larger height. In the back way, this transformed X-mode goes through the reflection level of the O-mode, and again turns into the O-mode. For polar latitudes, Jalonen [1981] established AFC properties with a characteristic decrease in the frequency difference between successive minima. On ionograms of the Cyclone ionosonde, sometimes there are two very deep minima (each with a small frequency extension) or one deep minimum (with a large frequency extension) in the frequency range below the region of beatings of the O- and X-modes. An example of the observation of such beatings is given in Figure 7 (arrows indicate two AFC minima).

The A-map of the $\mathrm{E}_{\mathrm{s}}$ layer (Figure 8) shows the time-frequency variations of the minima displayed in Figure 7. We can see that the variations of these minima form a "ring" pattern, which is similar to the variations of the zero beating point described in Sections 2.1 and 2.2. If the rings in Figure 8 are variations of the zero beating point, then the cause of these variations is most likely to be changes in the two reflection levels of the ordinary O-mode and the transformed O-mode, as shown in Figure 7, $b$ and described in [Chessel, 1971a, b; Jalonen, 1981].

As can be seen from Figure 8, the pattern in the form of "rings" is brighter for the beatings of two O-modes (that is, the amplitude of the "rings" often drops to zero) than for the beatings of the $\mathrm{O}$ - and $\mathrm{X}$-modes (Figure 6). 

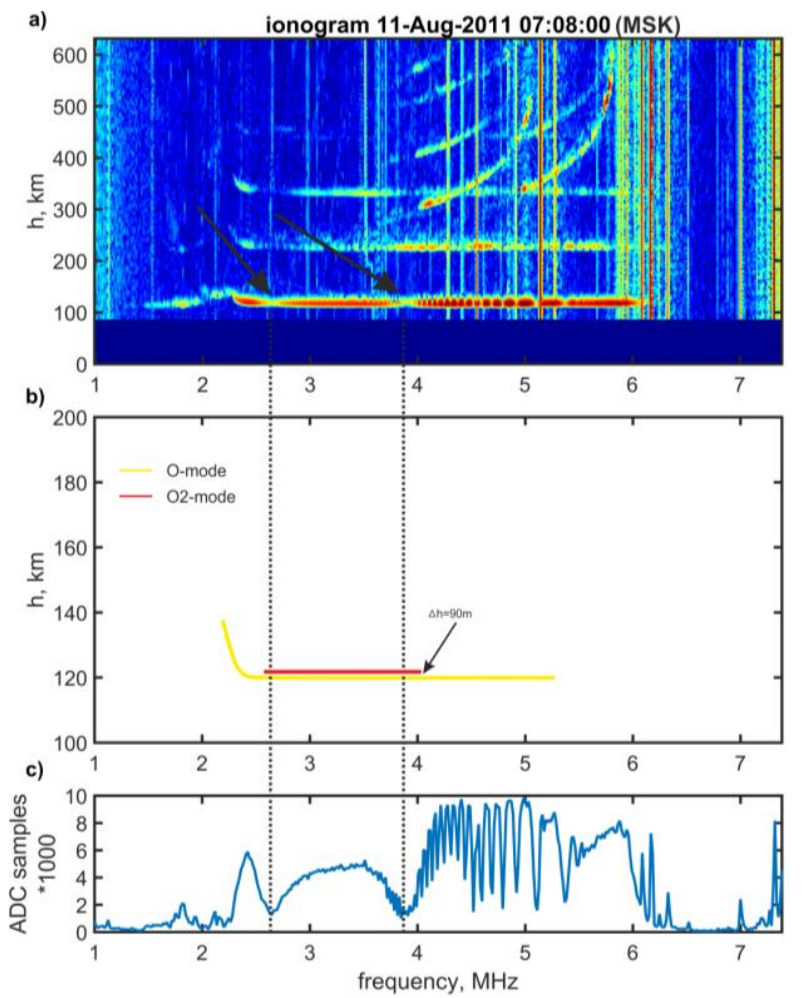

Figure 7. An ionogram with beatings of the type of two Omodes in Es-layer trace $(a)$; HFC of two Es-layer traces of Omodes (for clarity, the height axis is enlarged relative to the ionogram) $(b)$; c) $\mathrm{AFC}$ of the $\mathrm{E}_{\mathrm{s}}$ layer for the ionogram that depicts the polarization fading. Arrows indicate minima of the beatings of the type of two O-modes

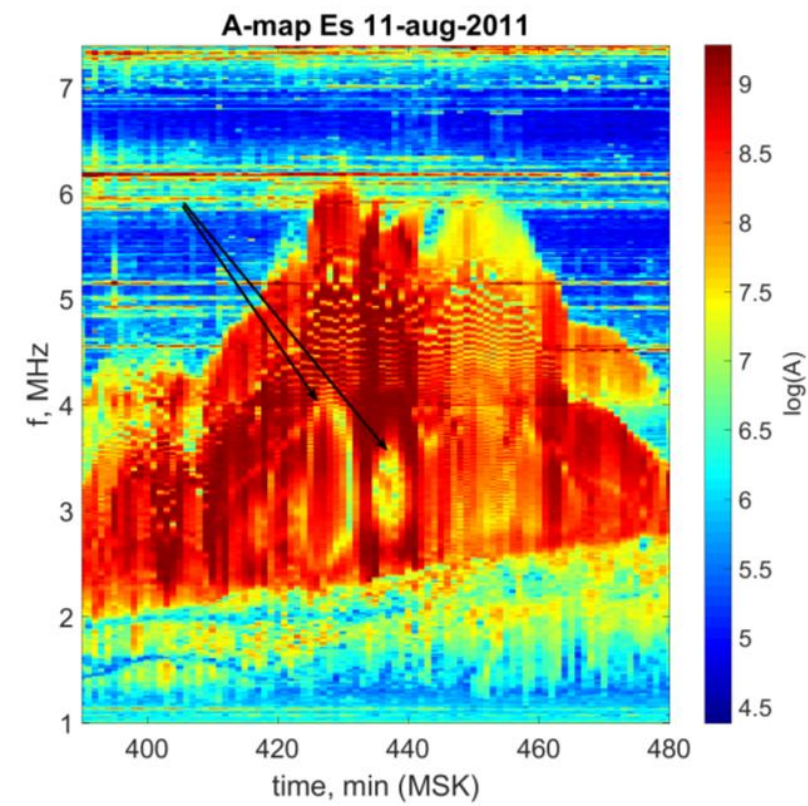

Figure 8. A-map of the Es layer showing patterns of the polarization fading as two O-modes in the form of "rings"

The frequency difference between the boundaries of the "ring" shows variations in the distance between two Otraces. These variations are due to changes in the background electron density of the E layer, as well as due to changes in the form of the $\mathrm{E}_{\mathrm{s}}$ electron density profile. In the time interval 423-427 min, the "rings" expanded and the diameter of the "ring" changed from $\sim 500 \mathrm{kHz}$ to
1.6 $\mathrm{MHz}$, which corresponds to a change in the difference between effective heights from $\sim 300 \mathrm{~m}$ to $\sim 90 \mathrm{~m}$ for $3 \mathrm{~min}$. Further, in the time interval $427-432 \mathrm{~min}$, the "ring" was compressed because the second O-mode of the trace moved away from the main one. Variations in the "ring diameter" usually correlate with variations in the critical frequency of the $\mathrm{E}_{\mathrm{s}}$ layer. Thus, beatings can be used to obtain additional information about the background concentration of the lower ionosphere. By calculating the virtual reflection heights of the O-mode of the $\mathrm{E}_{\mathrm{s}}$ layer and finding the characteristic points of the polarization fading through machine learning, we can calculate the form of the electron density profile of the lower part of the E layer.

\subsection{Signal beatings during reflection from the transient $\mathbf{E}_{\mathrm{s}}$ layer}

The transient sporadic layer is poorly known. It is distinguished from the usual $\mathrm{E}_{\mathrm{s}}$ layer by: 1) instantaneous appearance with a high limiting frequency (sometimes up to $25 \mathrm{MHz}$ or more) 2) a flat trace shape (without a cusp even in the daytime) 3) low amplitude of the reflected signal (often not much higher than the noise level ionograms). The lifetime of the transient $\mathrm{E}_{\mathrm{s}}$ layer varies from $\sim 1$ to $\sim 30 \mathrm{~min}$, while the intensity only decreases. Causes of the appearance of the transient layer are associated with meteors [Maruyama, 2006, 2008; Yusupov, 2017; Kozlovsky, 2018]. An example of an ionogram with the transient $\mathrm{E}_{\mathrm{s}}$ layer is given in Figure 9, $a$.

Beatings with approximately equal frequency differences between the minima are clearly visible on the ionogram. Figure 9, $b$ shows AFC of the reflected signal; dotted lines indicate frequencies of the minima. The difference between neighboring minima is $\Delta f \sim 162 \mathrm{kHz}$. As for other types of beatings, it is possible to obtain a difference in virtual heights $\Delta h \sim 925 \mathrm{~m}$. But what signals are reflected at different heights? Splitting the signal into magnetoionic components requires sufficient layer thickness for the appearance of anisotropy. In this case, AFC variations will be similar to the variations described in Section 2.2. However, as a rule, the thickness of the transient $\mathrm{E}_{\mathrm{s}}$ layer is insufficient for splitting the signal into magnetoionic components and the cause of

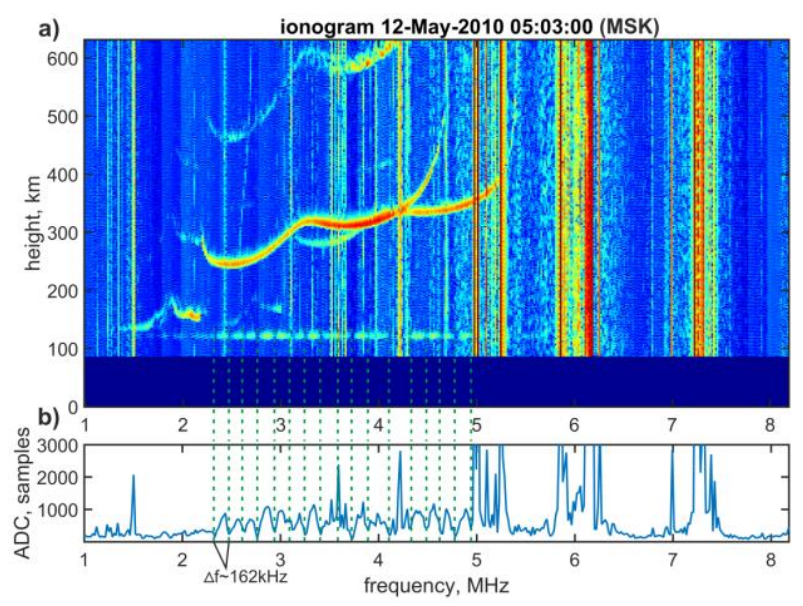

Figure 9. An ionogram with a transient $\mathrm{E}_{\mathrm{s}}$ trace 
such beatings as in Figure 9 may be the separation of the meteor into fragments [Mathews, 2010]. Each meteor fragment forms a transient layer, and $\Delta \mathrm{h}(\sim 925 \mathrm{~m})$ in this case shows the distance between the fragments. These layers cannot be separated on the ionogram; they can be detected only by beatings.

\subsection{Amplitude variations in reflected signals scattered by the E, Es, and F layers}

We should note the AFC variations arising from signal scattering. When scattered, a reflected signal becomes diffuse, has a duration longer than the sounding pulse, and can also extend into the frequency region above the critical one. Scattering during vertical sounding is associated with the multipath reflection of a sounding signal from the ionosphere by random irregularities of plasma concentration, when several signals return to the source through different paths, and therefore they are associated with different group delays [Tolstikov, 2004]. The first studies of spread-F were described in [Booker and Wells, 1938], then many works on this topic have been performed, for example [Antonov, 1987; Gershman, 1963; Vybornov, 1997; Muradov, Mukhametnazarova, 1982; Bowman, 1982; Renau, 1960; Booker, 1986]. The relationship between spread-F and spread-Es has been analyzed in [Mathews, 2001; Haldoupis, Haldoupis, 2011]. AFC during scattering looks chaotic and have very small frequency distances between minima/maxima, which is associated with multiple reflection of sounding signals from various types of irregularities. An example of an ionogram with such variations in AFC is given in Figure 10.

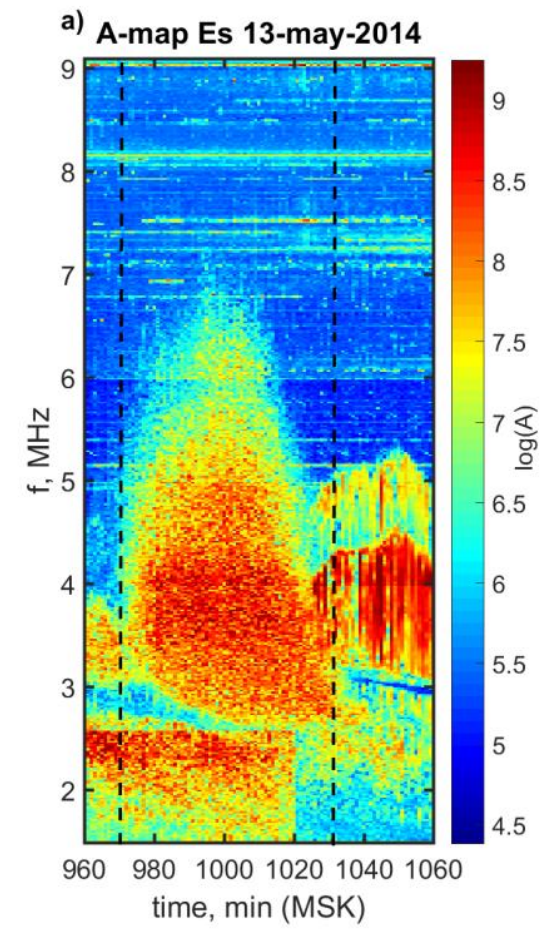

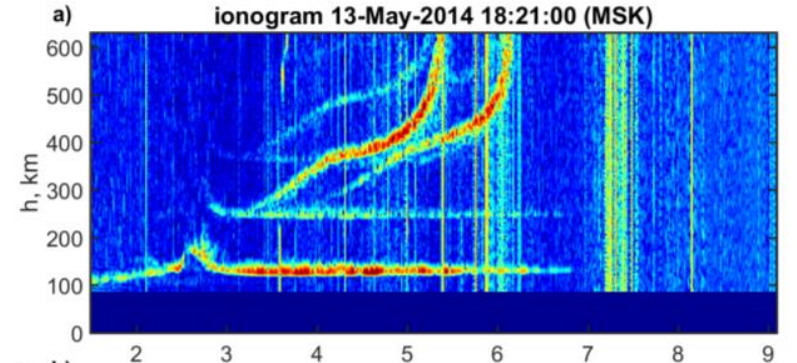
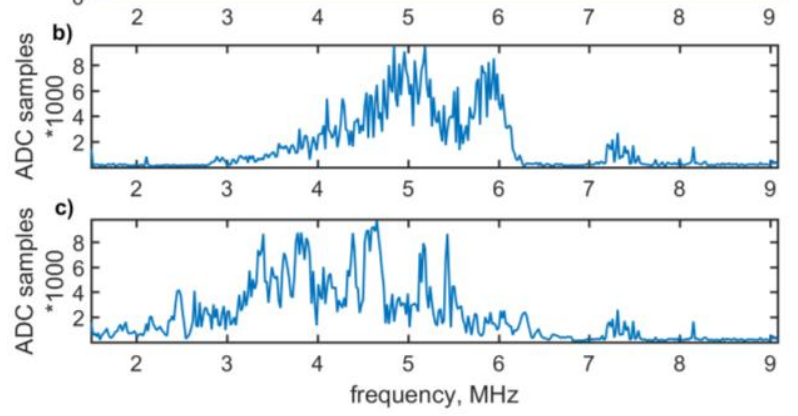

Figure 10. An ionogram showing traces of the $\mathrm{F}$ and $\mathrm{E}_{\mathrm{s}}$ layers with a fine random structure $(a)$; $\mathrm{AFC}$ of the $\mathrm{F}$ layer $(b)$; $\mathrm{AFC}$ of the $\mathrm{E}_{\mathrm{s}}$ layer $(c)$. These AFC clearly show the chaotic nature of the amplitude variations

Using A-maps, it is easy to determine the periods of appearance of scattering both for $\mathrm{E} / \mathrm{E}_{\mathrm{S}}$ traces (Figure 11, a) and for F-traces (Figure 11, b). In Figure 11, the time range when scattering was observed is indicated by vertical dashed lines. It is seen that at $\sim 970 \mathrm{~min}$ an $\mathrm{E}_{\mathrm{s}}$ layer appeared with scattering properties, and scattering occurred at the $\mathrm{F}$ layer in $\sim 15 \mathrm{~min}$. At $\sim 1023 \mathrm{~min}$, reflections from this $\mathrm{E}_{\mathrm{s}}$ layer began to disappear, and at the same time, scattering by the F trace stopped.

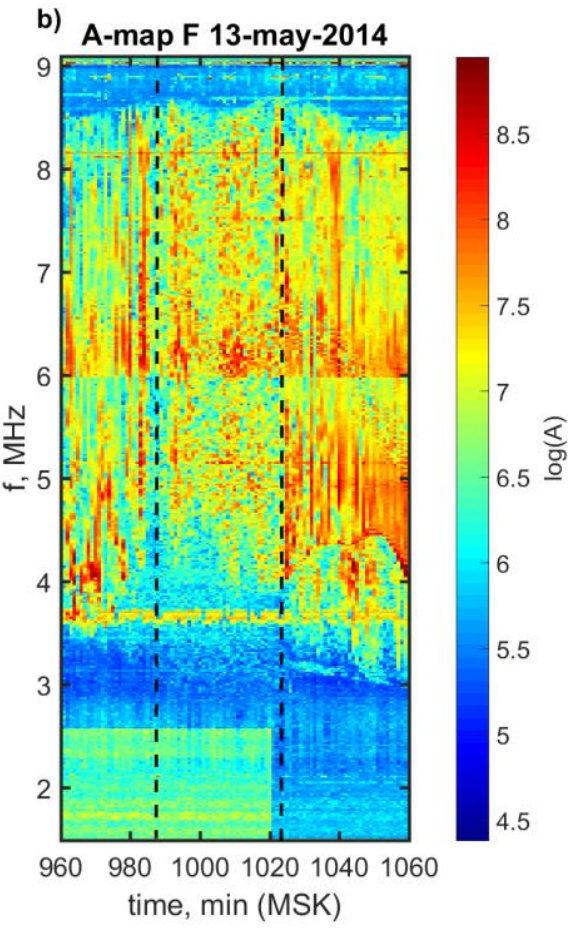

Figure 11. An A-map showing AFC variations during scattering for the E/Es $(a)$ and $\mathrm{F}(b)$ layers. Vertical dashed lines indicate the time interval of scattering 


\section{CONCLUSION}

The paper describes in detail the algorithm for constructing summary maps of the state of the ionosphere, considers and illustrates (with ionograms of the ionosonde Cyclone) all previously known beatings during vertical sounding of the ionosphere at middle latitudes, including interference beatings, rare for the mid-latitude $\mathrm{E}_{\mathrm{s}}$ layer, of the type of two $\mathrm{O}$ modes. We give examples of beatings during reflection of a signal from a transient $\mathrm{E}_{\mathrm{s}}$ layer and propose a hypothesis that explains causes of their occurrence. A meteor is divided into fragments, each forming a transient $\mathrm{E}_{\mathrm{s}}$ layer. These layers cannot be identified on the ionogram - they can be detected only by beatings. We show that at middle latitudes: 1) $\mathrm{O}$-and $\mathrm{X}$-mode beatings upon reflection from the $\mathrm{F}$ layer are observed both before and after the point of zero beatings; 2) the beatings of the $\mathrm{O}$ - and $\mathrm{X}$-modes when reflected from the $E_{s}$ layer in most cases is observed only before the point of zero beatings. 3) Beatings of two $\mathrm{O}$-modes during reflection from the $\mathrm{E}_{\mathrm{s}}$ layer in most cases are seen only around the point of zero beatings. Analysis of patterns of such a polarization fading makes it possible to determine with high accuracy the difference in virtual heights between ionogram traces of different polarizations. This information can be used to improve the accuracy of reconstructing the electron density profile of the lower ionosphere. We give typical examples of AFC for the spread-E/ $\mathrm{E}_{\mathrm{s}}$ and $-\mathrm{F}$.

This work was supported by the Russian Foundation for Basic Research, project No. 18-35-00442. In the work we used the analysis methods obtained in the framework of the basic funding of the program FNI II.12.

\section{REFERENCES}

Akchurin A.D., Yusupov K.M. Control system for ionosonde Cyclone. Nauchno-tekhnicheskie vedomosti SPbGPU [St. Petersburg State Polytechnical University Journal]. 2010, no. 108, pp. 49-56. (In Russian).

Akchurin A.D., Yusupov K.M. The frequency properties of the quasiperiodic variations of midlatitude $\mathrm{E}_{\mathrm{s}}$ layer traces amplitude. $2011 \mathrm{XXX}^{\text {th }}$ URSI General Assembly and Scientific Symposium. Istabbul, 2011a. P. 1-4. DOI: 10.1109/URSIGASS. 2011.6050993. https://ieeexplore.ieee.org/document/6050993? reload=true\&arnumber $=6050993$.

Akchurin A.D., Yusupov K.M. Frequency properties of quasi-periodical beatings at $\mathrm{AFC}$ of mid-latitude $\mathrm{E}_{\mathrm{s}}$ layer. Uchenye zapiski Kazanskogo universiteta [Proc. of Kazan University]. Ser. Phys. and Math. Sciences. 2011b, vol. 153, no. 1, pp. 7-16. (In Russian).

Antonov A.M., Nepomnyashchaya E.V., Fatkullin M.N. F-spread phenomenon in daytime mid-latitude ionosphere. Geomagnetizm i aeronomiya [Geomagnetism and Aeronomy]. 1987, vol. 27, no. 5, pp. 831-833. (In Russian).

Bakhmet'eva N.V., Belikovich V.V., Ignat'ev Y.A., Ponyatov A.A. Vertical motions in the lower ionosphere and a sporadic E layer. Radiophysics and Quantum Electronics. 1999, vol. 42, pp. 22-30. DOI: 10.1007/BF02677637.

Bakhmet'eva N.V., Belikovich V.V., Kagan L.M., Ponyatov A.A. Sunset-sunrise characteristics of sporadic layers of ionization in the lower ionosphere observed by the method of resonance scattering of radio waves from artificial periodic inhomogeneities of the ionospheric plasma. Radiophysics and Quantum Electronics. 2005, vol. 48, pp. 14-28. DOI: 10.1007/s11141005-0044-3.
Booker, H.G., Wells, H.W. Scattering of radio waves by the F region of the ionosphere. Terr. Magn. Atmos. Electr. 1938, vol. 43, no. 3, pp. 249-256. DOI: 10.1029/TE043i003p00249.

Booker H.G., Pasmicha P.K., Powers W.J. Use of scintillation theory to explain frequency-spread on F-region ionograms. J. Atmos. Terr. Phys. 1986, vol. 48, no. 4, pp. 327-354.

Bowman G.G. Spread-F occurrence in mid and lowlatitude regions related tovarious levels of geomagnetic activity. J. Atmos. Terr. Phys. 1982, vol. 44, no. 7.1, pp. 585-589.

Budden K.G. Radio Waves in the Ionosphere. Cambridge University Press, 1961. 542 p.

Chessel C.I. The numerical calculation of reflection and transmission coefficients for thin highly ionised layers including the effect of the Earth's magnetic field. J. Atmos. Terr. Phys. 1971a, vol. 33, p. 1515. DOI: 10.1016/0021-9169(71)90070-5.

Chessel C.I. Results of numerical calculation of reflection and transmission coefficients for thin highly ionised layers and their application to sporadic-E reflections. J. Atmos. Terr. Phys. 1971b, vol. 33, pp. 1803-1822. DOI: 10.1016/00219169(71)90161-9.

Chkhetiani O.G., Shalimov S.L. Mechanism by which frontal structures in the ionospheric sporadic E layers are formed. Geomagnetism and Aeronomy. 2013, vol. 53, no. 2, pp. 177-187. DOI: 10.1134/S0016793213020059.

Drobzhev V.I., Kudelin G.M., Nurgozhin V.I., Penelitsyn G.M., Rudina M.P., Troitsky B.V., Yakovets A.F. Volnovye vozmushcheniya $v$ ionosphere [Wave disturbances in the ionosphere]. Alma-Alta, Nauka, 1975. 178 p. (In Russian).

Gershman B.N., Kazimirovsky E.S., Kokourov V.D., Chernobrovkina N.A. F-rasseyanie v ionosphere [F-spread in the ionosphere]. Moscow, Nauka, 1984. 141 p. (In Russian).

Haldoupis C. Haldoupis C. A tutorial review on sporadic $E$ layers. Aeronomy of the Earth's Atmosphere and Ionosphere. IAGA Special Sopron Book Ser. Springer, Dordrecht, 2011, vol. 2. DOI: 10.1007/978-94-007-0326-1_29.

Haldoupis C., Kelley M.C., Hussey G.C., Shalimov S. Role of unstable sporadic- $E$ layers in the generation of midlatitude spread F. J. Geophys. Res. 2003, vol. 108, iss. A12, pp. 1446. DOI: 10.1029/2003JA009956.

Haldoupis C., Meek C., Christakis N., Pancheva D., Bourdillon A. Ionogram height-time-intensity observations of descending sporadic E layers at mid-latitude. J. Atmos. Solar-Terr. Phys. 2006, vol. 68, pp. 539-557. DOI: 10.1016/j.jastp.2005.03.020.

Harris T.J., Quinn A.D., Pederick L.H. The DST group ionospheric sounder replacement for JORN. Radio Sci. 2016, vol. 51, pp. 563-572. DOI: 10.1002/2015RS005881.

Jalonen L. Quasi-periodic frequency dependence of $E_{\mathrm{s}}$ - and E-layer echo amplitudes caused by mode coupling // J. Atmos. Terr. Phys. 1981, vol. 43, pp. 1285-1288. DOI: 10.1016/00219169(81)90153-7.

Kozlovsky A., Shalimov S., Kero J., Raita T., Lester M. Multi-instrumental observations of nonunderdense meteor trails. J. Geophys. Res.: Space Phys. 2018, vol. 123, iss. 7, pp. 59745989. DOI: $10.1029 / 2018 J A 025405$.

Lynn K.J.W., Otsuka Y., Shiokawa K. Simultaneous observations at Darwin of equatorial bubbles by ionosonde-based range/time displays and airglow imaging. Geophys. Res. Lett. 2011, vol. 38, pp. L23101. DOI: 10.1029/2011GL049856.

Maruyama T., Saito S., Yamamoto M., Fukao S. Simultaneous observation of sporadic $E$ with a rapid-run ionosonde and VHF coherent backscatter radar. Ann. Geophys. 2006, vol. 24, pp. 153-162. DOI: 10.5194/angeo-24-153-2006.

Maruyama T., Kato H., Nakamura M. Meteor-induced transient sporadic $\mathrm{E}$ as inferred from rapid-run ionosonde observations at midlatitudes. J. Geophys. Res. 2008, vol. 113, A09308. DOI: 10.1029/2008JA013362.

Mathews J.D. Sporadic E: Current views and recent progress. J. Atmos. Solar-Terr. Phys. 1998, vol. 60, pp. 413-435. DOI: 10.1016/S1364-6826(97)00043-6. 
Mathews J.D., Bekeny F.S. Upper atmosphere tides and the vertical motion of ionospheric sporadic layers at Arecibo. $J$. Geophys. Res. 1979, vol. 84, pp. 2743-2750. DOI: JA084iA06 p02743.

Mathews J.D., Machugaa D.W., Zhou Q. Evidence for electrodynamic linkages between spread-F, ion rain, the intermediate layer, and sporadic E: results from observations and simulations. J. Atmos. Solar-Terr. Phys. 2001, vol. 63, iss. 14, pp. 1529-1543. DOI: 10.1016/S1364-6826(01)00034-7.

Mathews J.D., Briczinski S.J., Malhotra A., Cross J. Extensive meteoroid fragmentation in V/UHF radar meteor observations at Arecibo Observatory. Geophys. Res. Lett. 2010 vol. 37, pp. L04103. DOI: 10.1029/2009GL041967.

Muradov A., Mukhametnazarova A. Quantitative characteristics of F-spread. Issledovaniya po geomagnetimu, aeronomii I fizike Solntsa [Res. on Geomagnetism, Aeronomy and Solar Physics]. 1982, iss. 59, pp. 24-28. (In Russian).

Renau Y.A. A study of observed spread-F. J. Geophys. Res. 1960, vol. 65, no. 10, p. 3219.

Shalimov S.L. Dynamics and electrodynamics of ionospheric inhomogeneities of the midlatitude E region (Review). Geomagnetism and Aeronomy. 2014, vol. 54, no. 2, pp.137151. DOI: 10.1134/S0016793214020170.

Sherstyukov O.N. Otrazhayushchaya sposobnost' sredneshirotnogo sloya $E$ [Reflection power of mid-latitude sporadic E layer]. PhD Thesis (Phys.\&Math.). Kazan, 1989, 200 p. (In Russian).

Tolstikov M.V. Dinamika volnovykh neodnorodnostei plazmy vneshnei ionosfery [Dynamics of Wave Plasma Inhomogeneities in the Outer Ionosphere]. PhD Thesis 01.04.03. Irkutsk, 2004, 106 p. RGB OD 61:04-1/1182. (In Russian).
Turunen T., Nygren T., Jalonen L. Observations of the reflection coefficient of the sporadic E-layer at high latitudes. $J$. Atmos. Terr. Phys. 1980, vol. 42, pp. 147-154. DOI: 10.1016/00219169(80)90074-4.

Vybornov F.I., Mityakova E.E., Rakhlin A.V. Behavior characteristics of the index of middle-latitude F-spread. Radiophysics and Quantum Electronics. 1997, vol. 40, pp. 206-209.

Whitehead J.D. Recent work on mid-latitude and equatorial sporadic-E. J. Atmos. Terr. Phys. 1989, vol. 51, pp. 401-424. DOI: 10.1016/0021-9169(89)90122-0.

Yusupov K.M. Fine structure of reflections from the sporadic E layer. PhD Thesis (Phys.\&Math.). 2011, 141 p. (In Russian).

Yusupov K., Maruyama T., Akchurin A., Sherstyukov O. Transient $E_{\mathrm{s}}$-layers 2013-2014. 2017 32nd General Assembly and Scientific Symposium of the International Union of Radio Science, URSI GASS 2017. 2017, vol. 2017-January, pp. 1-3. DOI: 10.23919/URSIGASS.2017.8105077.

How to cite this article

Yusupov K.M., Mathews J.D., Maruyama T., Akchurin A.A., Tolstikov M.V., Sherstyukov O.N., Filippova E.A., Safiullin A.S Amplitude variations of the reflected signal during vertical sounding of the ionosphere at middle latitudes. Solar-Terrestrial Physics. 2020. Vol. 6. Iss. 3. P. 72-80. DOI: 10.12737/stp-63202010. 